\title{
METODOLOGIA DE ACOMPANHAMENTO E COMBATE À EVASÃO: O CASO DO CURSO DE ENGENHARIA DE PRODUÇÃO DA UNESPAR
}

METHODOLOGY TO KEEP UP AND OPPOSE EVASION: THE CASE OF THE INDUSTRIAL ENGINEERING COURSE OF UNESPAR

Tainara Rigotti de Castro ${ }^{1}$

DOI: 10.37702/REE2236-0158.v40p114-127.2021

\begin{abstract}
RESUMO
Os elevados índices de evasão têm sido um problema enfrentado por diversas Instituições de Ensino Superior (IES), movimentando esforços de pesquisa no Brasil e no mundo, entretanto, sem a existência ainda de uma ação global que permita quantificar, sob um mesmo critério, a evasão e suas causas. Assumindo a Universidade Estadual do Paraná (UNESPAR) - Campus de Campo Mourão como case da pesquisa, foram levantadas informações sobre a evasão de estudantes no curso de graduação de Engenharia de Produção Agroindustrial (EPA). Nesse contexto, o objetivo da pesquisa foi desenvolver uma metodologia de acompanhamento e de combate à evasão (Metodologia CACE). A partir da aplicação das quatro etapas da metodologia proposta foi possível identificar os fatores ligados à evasão, bem como definir ações e estratégias institucionais que objetivaram combater os altos índices de evasão. Por meio da aplicação da metodologia proposta foi possível reduzir todos os índices de evasão do curso de EPA, superando as expectativas impostas pelas metas propostas.
\end{abstract}

Palavras-chave: evasão; metodologia; ações e estratégias.

\begin{abstract}
The high evasion rates have been a problem faced by several higher education institutions, moving research efforts in Brazil and in the world, however, without the existence of a global action that allows quantifying, under the same criterion, the evasion and its causes. Assuming the Universidade Estadual do Paraná (UNESPAR) - Campus of Campo Mourão - as a case of the research, information about the evasion of students in the Engenharia de Produção Agroindustrial (EPA) course was identified. In this context, the objective of the research was to develop a methodology for monitoring and combating evasion (Methodology CACE). From the application of the four phases of the proposed methodology was possible to identify the factors related to evasion, as well as to define institutional actions and strategies to decrease the high evasion rates. Through the application of the proposed methodology was possible to reduce all evasion rates in the EPA Course, exceeding the expectations imposed by the proposed goals.
\end{abstract}

Keywords: evasion; methodology; actions and strategies. 


\section{INTRODUÇÃO}

No Brasil, nos últimos anos, tem se observado o desenvolvimento de diversas políticas públicas de incentivo à educação superior, como o Programa Universidade para Todos (PROUNI), o Fundo de Financiamento Estudantil (FIES), o Programa de Reestruturação e Expansão das Universidades Federais (REUNI); além da ampliação da forma de ingresso por meio da utilização da nota do Exame Nacional do Ensino Médio (ENEM) para concorrência às vagas por intermédio do Sistema de Seleção Unificada (SISU). Outro fator de crescimento que contribuiu para a expansão universitária foi a criação do Sistema Universidade Aberta do Brasil (UAB) por meio da Educação a Distância (EaD) (SANTOS JUNIOR; REAL, 2017). Essas diversas iniciativas possibilitaram que o aluno pudesse acessar o ensino superior com mais facilidade; entretanto, tais esforços não se traduziram em números de egressos/estudantes concluintes (SANTOS, 2018).

De acordo com o Censo da Educação Superior de 2018 (BRASIL, 2019), mais de 13,5 milhões de vagas em cursos de graduação foram oferecidas; atingiu-se a marca de 8,45 milhões de alunos matriculados e 1,2 milhão de estudantes concluintes. Assim, torna-se claro que as salas de aula já recebem menos alunos do que o previsto no primeiro período; ou seja, qualquer que seja o número de evadidos, isso já representa uma taxa de ociosidade e perda financeira para a Instituição de Ensino Superior (IES) (MARTINS, 2007). Para Santos Junior e Real (2017), é justamente a partir do aumento dos números de vagas para a garantia do acesso ao ensino superior que a educação brasileira passou a atender aos percentuais de uma educação de massa, configurando a evasão como pauta da agenda pública brasileira.

O conceito de evasão considera estudantes que decidem se desligar de uma IES por sua própria responsabilidade (BUENO, 1993), seja por meio de abandono, trancamento, desligamento ou transferência para outra IES (RODRIGUES et al., 2017). O principal aspecto negativo da evasão é o aumento do custo unitário da formação dos estudantes, pois a mesma estrutura acadêmica e recursos humanos que deveriam atender um dado grupo inicial são destinados a um quantitativo menor de indivíduos (CARVALHO et al., 2018).

Além disso, a evasão diminui o engajamento dos alunos remanescentes e cria um ambiente de desmotivação. A motivação tem sido considerada importante - é o que a literatura tem apontado a partir da abordagem dos seus benefícios para o envolvimento acadêmico (PORTO; GONÇALVES, 2017; ZENORINI; SANTOS; MONTEIRO, 2011; GUIMARÃES; BORUCHOVITCH, 2004).

Os elevados índices de evasão têm sido um problema enfrentado por diversas IES, movimentando esforços de pesquisa no Brasil e no mundo com finalidades diversas, como a elaboração de modelos matemáticos para prever alunos propensos à desistência, identificação da tipologia de alunos não tradicionais/com tendência à desistência, intervenção para redução da evasão, identificação do perfil de acadêmicos, identificação de taxas de evasão e variáveis que influenciam esse indicador (MORTAGY; BOGHIKIAN-WHITBY; HELOU, 2018; SÁNCHEZ-GELABERT; ANDREU， 2017; BAR-AM; ARAR, 2017; ALVES; MONTOVANI, 2016; ARCE; CRESPO; MIGUEZ-ÁLVAREZ, 2015; MIWA; SHIMOSEGAWA, 2015; BREIER, 2010).

No Brasil, as pesquisas sobre a evasão se tornaram mais frequentes a partir de 1995, quando a Comissão Especial de Estudos sobre Evasão foi constituída, através de Portaria SESU/MEC; entretanto, ainda sem a existência de uma ação global que permitisse quantificar, sob um mesmo critério, a evasão e suas causas (UFPE, 2016).

Diante dessa problemática e assumindo a Universidade Estadual do Paraná (UNESPAR) - Campus de Campo Mourão - como case da pesquisa, foram levantadas informações sobre a evasão de estudantes no curso de graduação de Engenharia de Produção Agroindustrial (EPA). Nesse contexto, o objetivo da pesquisa foi desenvolver uma metodologia de acompanhamento e de combate da evasão (Metodologia CACE) que, a partir do conhecimento de fatores diversos, tornasse possível definir ações e estratégias 
institucionais com o objetivo de combater índices de evasão.

\section{METODOLOGIA CACE}

A Metodologia CACE tem o objetivo de combater a evasão no ensino superior por meio de um ciclo de quatro etapas: 1) Coletar (C);2) Analisar (A); 3) Combater (C); e 4) Examinar (E). Esse ciclo deve ser aplicado anualmente; ou seja, as atividades devem ser desenvolvidas no decorrer de um ano (ou no decorrer de seis meses, caso o curso seja semestral), com vistas à análise da evasão do período precedente. É indispensável, para que a Metodologia seja colocada em prática, a formação de uma equipe executora composta por alunos e professores. Salienta-se que esse ciclo busca a melhoria contínua, ou seja, trata-se de uma prática que visa a atingir ininterruptamente resultados cada vez melhores. A Figura 1 ilustra as etapas da Metodologia CACE. O Quadro 1 elenca as atividades que compõem cada uma das etapas.

Figura 1 - Etapas da Metodologia CACE

\begin{tabular}{|l|l|}
\hline 4. Examinar & 1. Coletar \\
3. Combater & 2. Analisar \\
\hline
\end{tabular}

Fonte: acervo da autora.

Quadro 1 - Etapas e suas atividades

\begin{tabular}{|l|l|}
\hline \multicolumn{1}{|c|}{ ETAPA } & \multicolumn{1}{c|}{ ATIVIDADES } \\
\hline 1. Coletar & 1.1 Identificação dos evadidos \\
& 1.2 Alocação dos evadidos em grupos \\
& 1.3 Comunicação com os evadidos \\
\hline 2. Analisar & $\begin{array}{l}\text { 2.1 Tabulação de dados } \\
\text { 2.2 Cálculo dos índices de evasão } \\
\text { 2.3 Fixação de metas }\end{array}$ \\
\hline 3. Combater & 3.1 Planejamento ações de combate \\
& 3.2 Prática de ações de combate \\
\hline 4. Examinar & 4.1 Discussão com acadêmicos \\
\hline
\end{tabular}

Fonte: elaborado pela autora.
A primeira etapa $(\mathrm{C}-$ Coletar $)$ tem por objetivo coletar os dados necessários que embasarão as etapas posteriores. Essa etapa é composta por três atividades: 1.1 Identificação dos evadidos; 1.2 Alocação dos evadidos em grupos; e, 1.3 Comunicação com os evadidos.

A atividade 1.1, identificação dos alunos evadidos, deve ser realizada por meio da pesquisa documental a fim de selecionar todos os alunos evadidos durante um dado ano $\mathrm{X}$. Ressalta-se que é considerado como evadido qualquer aluno que tenha abandonado seu curso de origem sem concluí-lo (BRASIL, 1996). Os documentos que devem ser acessados são aqueles utilizados pela IES contidos de informações relativas aos alunos aprovados, num dado ano $\mathrm{X}$, nos processos seletivos para ingresso de alunos, tais como: listas de alunos aprovados, relações de alunos ingressantes matriculados, relações de alunos matriculados em disciplinas, sistemas de controle acadêmico entre outros. Cabe ressaltar que o dado ano $\mathrm{X}$ se refere ao período de análise, sendo caracterizado por ser precedente ao ano cujo ciclo é colocado em prática; por exemplo, se a Metodologia for aplicada no decorrer do ano de 2020, o dado ano X (ano de análise) será o ano precedente (2019).

Depois de identificados os evadidos, a atividade 1.2 deve ser realizada - os alunos evadidos devem ser alocados em grupos de acordo com suas características (Quadro 2).

\section{Quadro 2 - Descrição dos Grupos de alunos} evadidos

\begin{tabular}{|c|l|}
\hline GRUPO & \multicolumn{1}{|c|}{ DESCRIÇÃO } \\
\hline \multirow{2}{*}{ Grupo 1 } & $\begin{array}{l}\text { Composto por alunos ingressantes, } \\
\text { num dado ano X, que frequentaram } \\
\text { o curso e se evadiram, no mesmo } \\
\text { ano }\end{array}$ \\
\hline \multirow{3}{*}{ Grupo 2 } & $\begin{array}{l}\text { Composto por alunos aprovados e } \\
\text { matriculados, num dado ano X, que } \\
\text { nunca frequentaram o curso }\end{array}$ \\
\hline \multirow{3}{*}{ Grupo 3 } & $\begin{array}{l}\text { Composto por alunos aprovados, } \\
\text { num dado ano X, que não se } \\
\text { matricularam }\end{array}$ \\
\hline Grupo 4 & $\begin{array}{l}\text { Composto pelos demais evadidos } \\
\text { num dado ano X (alunos } \\
\text { ingressantes em anos/ períodos } \\
\text { precedentes ao dado ano X) }\end{array}$ \\
\hline
\end{tabular}

Fonte: elaborado pela autora.

A atividade 1.3 visa à comunicação com os evadidos dos Grupos 1 e 4, visto que eles são os

Etapa C - Coletar 
que realmente frequentaram o curso e, portanto, possuem informações relevantes sobre este. Para que a comunicação seja efetiva é necessário identificar fontes de acesso aos alunos - tais como: e-mail, telefone e redes sociais (esses dados podem ser encontrados no banco de dados da IES) -, com a finalidade de que seja enviado para eles o questionário de detecção dos fatores que os levaram à evasão (Quadro 3). O questionário foi dividido em três partes. A parte um foi composta por perguntas que objetivam caracterizar os entrevistados e suas perspectivas. A segunda parte do questionário foi elaborada com o intuito de caracterizar os fatores que os influenciaram à evasão. A parte três objetivou caracterizar a evasão em si. A segunda parte foi baseada em Brasil (1996), que descreve os fatores que influenciam a evasão no ensino superior: i) Fatores internos às instituições: podem se caracterizar por questões peculiares a própria academia, a falta de clareza sobre o projeto pedagógico do curso, baixo nível de didática pedagógica, cultura institucional de desvalorização da docência e estrutura insuficiente de apoio ao ensino;

ii) Fatores externos às instituições: mercado de trabalho, reconhecimento social na carreira escolhida, desvalorização da profissão, dificuldade de atualizar-se perante as evoluções tecnológicas, econômicas e sociais da contemporaneidade e políticas governamentais; iii) Fatores característicos individuais do estudante: habilidades de estudo, personalidade, formação escolar anterior, escolha precoce da profissão, dificuldades pessoais de adaptação à vida universitária, desencanto com o curso escolhido, dificuldades recorrentes de reprovações ou baixas frequências e desinformação a respeito da natureza dos cursos.

Quadro 3 - Questionário de detecção dos fatores da evasão

PARTE 1 - CARACTERIZAÇÃO PESSOAL E PERSPECTIVAS

\section{Nome:}

2. Sexo: () $\mathrm{F}(\mathrm{)}) \mathrm{M}$

3. Idade:

4. Estado Civil:

5. Qual sua ocupação atual? ( ) Estudante ( ) Empregado ( ) Outra, Qual?

6. Com quem você mora? ( ) República ( ) Com meus pais ( ) Com outros familiares ( ) Outro, Qual?

7. Você ajuda nas despesas da casa? ( ) Sim ( ) Não

8. Por que escolheu iniciar o Curso ao qual se evadiu?

9. Fez cursinho pré-vestibular? ( ) Sim ( ) Não

10. Sua família te apoiou na escolha desse curso? Por quê?

11. Quantos vestibulares realizou antes de ingressar nesse Curso? Para quais cursos e faculdades?

12. Você está estudando? Caso afirmativo, qual curso e instituição?

13. Caso esteja estudando, está satisfeito no curso? ( ) Sim ( ) Não Por quê?

PARTE 2 - FATORES QUE INFLUENCIARAM A EVASÃO

\section{a) Fatores externos à Instituição}

14. Como você avalia o mercado de trabalho para o profissional que possui a formação do Curso ao qual você se evadiu?

15. Esse profissional é reconhecido pelo que faz? Por quê?

\section{b) Fatores internos à Instituição}

16. O Curso ao qual você se evadiu sediou algum evento para a acolhida de calouros? Caso afirmativo, ele cumpriu seu propósito? Por

quê? No que deveria melhorar?

17. Como era seu relacionamento com seus colegas de Curso?

18. Como era seu relacionamento com os professores do Curso?

19. Como você avalia o nível didático pedagógico dos professores do Curso?

20. Você tinha facilidade de acesso a informações que beneficiariam e estimulariam sua permanência no Curso (monitorias, acesso a professores, estudos em grupos, entre outros)? Qual sua visão sobre isso?

\section{c) Fatores individuais do estudante}

21. Quais os maiores impactos na mudança do ensino médio para o superior?

22. Você sentiu dificuldades de adaptação à vida universitária? Caso afirmativo, quais?

23. Quais as disciplinas do Curso você tinha mais dificuldade, por quê?

24. Como eram suas notas?

25. Como eram suas frequências nas aulas das disciplinas as quais frequentava?

26. Qual sua intensidade de dedicação ao curso?

27. Você trabalhava ou trabalhou durante o tempo que frequentou o Curso?

28. O Curso era o que você esperava? Por quê?

\section{PARTE 3 - CARACTERIZAÇÃo DA EVASÃO}

29. Defina o motivo de sua desistência.

30. Em quais pontos o Curso de EPA poderia melhorar?

31. Você se arrependeu da decisão tomada (desistência)? Por quê?

32. Se pudesse fazer algo diferente na graduação, o que seria?

Fonte: Elaborado a partir de BRASIL (1996). 


\section{Etapa A - Analisar}

A segunda etapa (A - Analisar) tem por objetivo medir a evasão e planejar ações de acordo com as informações coletadas. De acordo com Lobo (2012), medir a evasão não se trata apenas de verificar quantos alunos entraram menos quantos saíram, mas quem entrou e quem saiu e por quais razões, o que torna possível evitar outras perdas pelos mesmos motivos a partir de ações que gerem mudanças. Estas, por sua vez, só acontecem se entendermos, claramente, o que está ocorrendo. Essa etapa é composta por três atividades: 2.1 Tabulação de dados; 2.2 Cálculo dos índices de evasão; e 2.3 Fixação de metas.

A Atividade 2.1 (tabulação dos dados) tem por finalidade o tratamento estatístico e análise do questionário de detecção aplicado na etapa anterior. Por meio da tabulação é possível identificar quais os principais problemas que levaram os alunos a se evadirem.

A Atividade 2.2 (cálculo dos índices de evasão) permite calcular a porcentagem da evasão e deve ser realizada em três etapas: 1) cálculo da evasão dos ingressantes (considerando os grupos 1 e 2), por meio da Equação 1;2) cálculo da evasão dos demais evadidos (grupo 4), por meio da Equação 2; 3) cálculo da evasão total do curso (considerando os grupos 1, 2 e 4), por meio da Equação 3. Ressalta-se que tais equações são utilizadas como cálculo básico e foram adaptadas de Prim e Fávero (2013) e Brasil (1996).

$$
\% \text { Evasãoingressantes }=\left(\mathrm{N}_{\mathrm{ie}} / \mathrm{N}_{\mathrm{i}}\right) \times 100
$$

Em que $\mathrm{N}_{\text {ie }}$ é o número de ingressantes evadidos e $\mathrm{N}_{\mathrm{i}}$ é o número de ingressantes em um dado ano $\mathrm{X}$.

$$
\% \text { Evasãodemais estudantes }=\left(\mathrm{N}_{\mathrm{e}} / \mathrm{N}_{\mathrm{m}}\right) \times 100
$$

Em que $\mathrm{N}_{\mathrm{e}}$ é o número de estudantes evadidos em um dado ano $\mathrm{X}$ (excluindo os ingressantes) e $\mathrm{N}_{\mathrm{m}}$ é o número de matriculados (excluindo os ingressantes).

$$
\% \text { Evasãototal do curso }=\left(\mathrm{N}_{\mathrm{te}} / \mathrm{N}_{\mathrm{ti}}\right) \times 100
$$

Em que $\mathrm{N}_{\text {te }}$ é o número total de evadidos em um dado ano $\mathrm{X}$ e $\mathrm{N}_{\mathrm{ti}}$ é o número total de ingressantes em um dado ano $\mathrm{X}$.

A atividade 2.3 (fixação de metas) consiste em fixar índices de evasão aceitáveis para o próximo período de análise. Suponha-se que se o índice de evasão de ingressantes num determinado curso seja de $35 \%$ em um dado ano, a meta a ser atingida poderia ser de $25 \%$ para o próximo período. Entretanto, ressalta-se que o índice a ser fixado deve ser estudado pelos envolvidos na aplicação da Metodologia de acordo com os recursos e realidade do curso em questão. As metas ainda podem envolver um número mínimo de ações realizadas em um período de tempo ou um número mínimo de alunos que farão parte da equipe executora, por exemplo.

A partir da aplicação do segundo ciclo, os índices calculados devem ser comparados às metas fixadas no período anterior. Essa comparação servirá de base para quantificação da eficiência das ações realizadas no período anterior, fixação de uma nova meta e planejamento dos novos esforços envolvidos.

\section{Etapa C - Combater}

A terceira etapa $(\mathrm{C}-\mathrm{Combater})$ tem por objetivo planejar as ações que serão capazes de diminuir os índices de evasão, bem como colocá-las em prática. Essa etapa é composta por duas atividades: 3.1 Planejamento das ações de combate; e 3.2. Prática de ações de combate.

A atividade 3.1 (planejamento das ações de combate) tem por objetivo elencar ações que visem a combater os problemas detectados por meio da Atividade 2.1 (tabulação dos dados), a fim de reduzir o índice de evasão atual e atingir a meta fixada na atividade 2.3. Por exemplo, caso seja detectado que a maioria dos entrevistados acusa uma negatividade em relação ao mercado de trabalho, cabe a realização de palestras com profissionais da área, direcionadas aos alunos, a fim de estimular a formação, além de informação sobre as características positivas de tal mercado de trabalho. O plano de ação $5 \mathrm{~W} 1 \mathrm{H}$ é uma ferramenta da qualidade que pode ser utilizada como norteadora nessa circunstância, já que é uma forma organizada de identificar as ações a 
serem executadas, através de um questionamento, capaz de orientar as diversas ações que deverão ser implementadas (PEINADO; GRAEML, 2007). O nome da ferramenta, de acordo com Martins e Laugeni (2005), é decorrente das palavras de origem inglesa com as iniciais $\mathrm{W}$ e $\mathrm{H}$ (what, why, who, where, when e how), cada uma delas relacadiona a um fundamento:

a) What? (o que?): o que será feito para resolver o problema;

b) Why? (por quê?): a razão/motivo de ser executado;

c) Who? (quem?): quem será designado para tentar resolver o problema;

d)Where? (onde?): o local onde será executado;

e) When? (quando?): o período/tempo em que será feito;

f) How? (como?): a forma/método como será executada a resolução.

As respostas para essas perguntas são geradas por meio da utilização da técnica Brainstorming (tempestade de ideias) que consiste em uma reunião em grupo a qual tem por finalidade a geração de ideias para proposição de soluções a um problema específico (PEINADO; GRAEML, 2007). Geralmente, as respostas para as perguntas do plano 5W1H são elencadas dentro de um quadro, com o intuito de se sistematizar a utilização da ferramenta (Figura 2).

Figura 2 - Ilustração do plano de ação 5W1H

\begin{tabular}{|c|c|c|c|c|c|}
\hline $\begin{array}{c}\text { O } \\
\text { que? }\end{array}$ & $\begin{array}{c}\text { Por } \\
\text { quê? }\end{array}$ & Quem? & Onde? & Quando? & Como? \\
\hline & & & & & \\
\hline & & & & & \\
\hline
\end{tabular}

Fonte: acervo da autora.

A atividade 3.2 (prática de ações de combate) objetiva colocar em prática o plano de ação definido.

\section{Etapa E - Examinar}

A quarta e última etapa (E - Examinar) tem por objetivo examinar a eficiência das ações realizadas e é composta por uma atividade: 4.1 Discussão com acadêmicos. Essa atividade tem por objetivo acompanhar a efetividade das ações realizadas ao longo do ano; ou seja, consultar os acadêmicos em relação ao que foi feito, em quais quesitos se pode melhorar ou até mesmo sobre sugestões de novas ações. Esse contato pode ser realizado por meio de reuniões, aplicação de questionários, batepapos entre outros. O feedback fornecido pelos alunos pode ser de grande valia para o aprimoramento das ações do próximo ciclo a fim de se atingir a meta pré-estipulada.

\section{Cronograma das Etapas}

Com a quantidade de atividades envolvidas na aplicação da Metodologia CACE, é necessário um planejamento por intermédio de cronograma. A Figura 3 disponibiliza uma sugestão de cronograma em que os períodos são orientados por trimestres. É apropriado que as etapas C (Coletar) e A (Analisar) sejam realizadas ainda no primeiro trimestre, visto que as informações adquiridas servirão de suporte para as demais atividades. A etapa $\mathrm{C}$ (Combater) é a que necessita de mais tempo para a execução, visto que é nela que se concentram o desenvolvimento das ações responsáveis pela diminuição do índice de evasão, sendo interessante que elas se estendem por todo o período letivo. Por fim, a etapa E é a que menos necessita de tempo e planejamento para sua realização.

Figura 3 - Sugestão de cronograma para o desenvolvimento da Metodologia CACE

\begin{tabular}{|l|c|c|c|c|}
\cline { 2 - 5 } \multicolumn{1}{c|}{} & \multicolumn{4}{c|}{ PERÍODO } \\
\hline ETAPA & $\begin{array}{c}1^{\circ} \\
\text { trimestre }\end{array}$ & $\begin{array}{c}2^{\circ} \\
\text { trimestre }\end{array}$ & $\begin{array}{c}3^{\circ} \\
\text { trimestre }\end{array}$ & $\begin{array}{c}4^{\circ} \\
\text { trimestre }\end{array}$ \\
\hline $\begin{array}{l}\text { C- } \\
\text { Coletar }\end{array}$ & $\mathrm{X}$ & & & \\
\hline $\begin{array}{l}\mathrm{A}- \\
\text { Analisar }\end{array}$ & $\mathrm{X}$ & & & \\
\hline $\begin{array}{l}\mathrm{C}- \\
\text { Combater }\end{array}$ & & $\mathrm{X}$ & $\mathrm{X}$ & $\mathrm{X}$ \\
\hline $\begin{array}{l}\text { E- } \\
\text { Examinar }\end{array}$ & & & & $\mathrm{X}$ \\
\hline
\end{tabular}

Fonte: acervo da autora. 


\section{A EVASÃO DO CURSO DE EPA DA UNESPAR}

O curso de Engenharia de Produção Agroindustrial (EPA) da UNESPAR foi inaugurado em 1998 em decorrência da necessidade de profissionais capacitados para atuar em Campo Mourão/PR e região, visto que nessas localidades estão instaladas importantes empresas agroindustriais dos segmentos de carnes, grãos e produtos industrializados.

$\mathrm{O}$ curso oferece anualmente 40 vagas em período integral, apresenta duração mínima de cinco anos e tem por objetivo formar profissionais com visão sistêmica, capazes de atuar em todos os elos das diversas cadeias de produção agroindustrial. O curso possui carga horária total de 4.454 horas/aula, contemplando 306 horas de Estágio Curricular Supervisionado, que deve ser realizado no último semestre, após o cumprimento de todas as disciplinas (FECILCAM, 2010).

Nos últimos anos, tem se observado as salas de aulas cada vez mais vazias, tanto pela queda do número de ingressantes quanto pelo aumento do número de desistentes. Isso refletiu diretamente no número total de matriculados anualmente no curso, conforme se observa na Figura 4, em que o total de matriculados no ano de 2019 é $42,86 \%$ menor quando comparado ao ano de 2011.

Figura 4 - Quantidade de matriculados/ano no Curso de EPA da UNESPAR

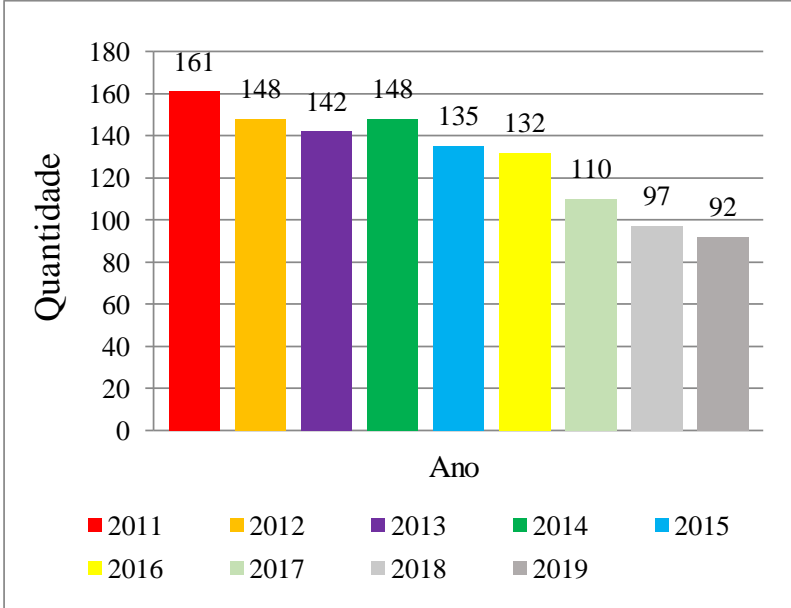

Fonte: acervo da autora.

Assim, no ano de 2017 foram realizados os primeiros cálculos relativos à evasão (referentes ao ano de 2016), dispostos na
Tabela 1. Este ano foi dedicado a pesquisas bibliográficas e literárias e concepção da Metodologia CACE.

Tabela 1 - Resultados relativos à evasão de alunos no ano de 2016

\begin{tabular}{l|c}
\hline \multicolumn{1}{c|}{ VARIÁVEIS } & ÍNDICES \\
\hline Total de ingressantes & 29 \\
\hline $\begin{array}{l}\text { Aproveitamento de vagas } \\
\text { disponibilizadas (\%) }\end{array}$ & 72,50 \\
\hline \%Evasão & 62,10 \\
\hline \%Evassantes & 13,54 \\
\hline \%Evasão ototal do curso $_{\text {to }}$ estudantes & 24,24 \\
\hline
\end{tabular}

Fonte: elaborada pela autora.

\section{Aplicação da metodologia CACE no curso de EPA}

$\mathrm{O}$ case aqui apresentado se refere à aplicação da Metodologia no decorrer do ano de 2018 , objetivando a coleta de dados referentes ao evadidos durante o ano de 2017.

$\mathrm{O}$ primeiro passo, para dar início à aplicação da Metodologia CACE, foi formar uma equipe executora composta por acadêmicos e professores do curso de EPA, além de um cronograma de planejamento e definição de responsabilidades. $O$ trabalho dessa equipe foi formalizado por meio de um Projeto de Pesquisa, no qual, mais tarde, percebeu-se a necessidade da criação de um Programa de Extensão, haja vista a necessidade de que fossem realizadas ações que envolvessem o público externo às IES.

\section{Aplicação da etapa C - Coletar}

A atividade 1.1 (identificação dos evadidos) foi realizada por meio do acesso ao sistema de controle acadêmico da universidade, lista dos alunos aprovados para ingresso na IES no curso de EPA e relações de alunos matriculados em disciplinas. Após identificados, os evadidos foram alocados em grupos (atividade 1.2), conforme Quadro 4. 
Quadro 4 - Composição dos Grupos de evadidos no ano de 2017

\begin{tabular}{|c|c|}
\hline GRUPOS & QUANTIDADE \\
\hline Grupo 1 & 20 \\
\hline Grupo 2 & 4 \\
\hline Grupo 3 & 110 \\
\hline Grupo 4 & 11 \\
\hline
\end{tabular}

Fonte: elaborado pela autora.

Ressalta-se que, naquele ano, 134 candidatos estavam aptos a ingressar no curso, visto que todos eles foram convocados (em listas de $2^{\mathrm{a}}, 3^{\mathrm{a}}, 4^{\mathrm{a}}$ e $5^{\mathrm{a}}$ chamadas). Destes, $31 \mathrm{se}$ matricularam, resultando numa evasão de 24 deles.

Por fim, os evadidos (grupos 1 e 4) foram contatados e o envio dos questionários foi realizado (atividade 1.3). O índice de retorno dos questionários foi de $41,67 \%$ em relação ao grupo 1 e de 54,55\% em relação ao grupo 4 . Ressalta-se a facilidade de contatar os entrevistados em razão do amplo acesso, por meio de redes sociais e aplicativos. Foram realizadas até três tentativas de comunicação por entrevistado (por meio de Facebook, WhatsApp e e-mail) e, mesmo assim, observase um baixo índice de retorno.

\section{Aplicação da etapa A - Analisar}

Primeiramente, os dados coletados foram tabulados (atividade 2.1) possibilitando a identificação dos principais problemas indicados pelos entrevistados, sendo eles:

a) falta de informação e conhecimento de particularidades a respeito do mercado de trabalho e da profissão do engenheiro de produção;

b) frustração com o curso (infraestrutura, núcleo de disciplinas ofertadas, carga horária, etc.);

c) dificuldade de adaptação ao ensino superior (rotina de estudos, necessidade de altos níveis de dedicação, etc.)

d) notas baixas em disciplinas, baixos níveis de motivação e dificuldade em determinados conteúdos.

A partir de uma análise mais acurada dos fatores identificados, foi possível constatar características distintas entre os grupos entrevistados e que, consequentemente, os integrantes de cada grupo possuíam fatores distintos que os levaram à evasão. É óbvio dizer que o grupo 1 é formado por jovens que acabam de ingressar na universidade, ainda imaturos; enquanto o grupo 2 é formado por pessoas com mais idade, que já passaram pela fase de ingresso e descobertas. Afirma-se isso pelo fato de que a maioria dos entrevistados do grupo 1 ingressaram no curso sem ao menos saber particularidades a respeito dele ou da profissão do engenheiro de produção e se evadiram para outras IES e/ou outros cursos, ou até mesmo pelo fato de terem visto colegas desistindo. No grupo 4 foi possível constatar que a maioria dos entrevistados entendem aspectos da profissão e do mercado de trabalho e se evadem por dificuldades geográficas, psicológicas, de aprendizado, financeiras, etc.

Quanto aos fatores externos à instituição, observou-se que os entrevistados do grupo 4 eram mais otimistas em relação à profissão do engenheiro de produção e ao mercado de trabalho do que os entrevistados do grupo 1 . Entretanto, a maioria dos entrevistados de ambos os grupos mostraram positividade em relação a esses aspectos.

Quanto aos fatores internos à instituição, não foram detectados problemas de relacionamento entre colegas de curso ou problemas entre alunos e professores.

Quanto aos fatores individuais do estudante, percebeu-se, em ambos os grupos, a presença de entrevistados com níveis de intensidade de dedicação e frequência nas aulas que deixavam a desejar, o que pode ter levado às notas baixas. Isso também pode estar relacionado à certa preparação que advém do Ensino Médio.

De modo geral, ficou claro que muitos dos evadidos (grupo 1) ingressaram no curso de EPA à espera de aprovação em outros cursos e/ou em outras IES, não se dedicando integralmente ou como deveriam. Quando aprovados, evadem-se para outros cursos; quando não aprovados, evadem-se pelo desânimo das notas baixas. Outros, diante dessa situação, sentem-se desmotivados e desistem pelo desânimo de ver tantos colegas se evadindo. Ressalta-se que as IES privadas absorvem em maior proporção alunos do grupo 
4, visto que estes, geralmente, transferem suas matrículas após anos de estudos no curso.

Em seguida, os índices de evasão (Tabela

2) foram calculados (atividade 2.2).

Tabela 2 - Resultados relativos à evasão de alunos no ano de 2017

\begin{tabular}{l|c}
\hline \multicolumn{1}{c|}{ VARIÁ VEIS } & ÍNDICES \\
\hline Total de ingressantes & 31 \\
\hline $\begin{array}{l}\text { Aproveitamento de vagas } \\
\text { disponibilizadas (\%) }\end{array}$ & 77,50 \\
\hline \%Evasãoingressantes & 77,42 \\
\hline \%Evasãodemais estudantes & 13,92 \\
\hline \%Evasãototal do curso & 31,82 \\
\hline
\end{tabular}

Fonte: elaborada pela autora.

Em comparação com os dados relativos ao ano de 2016 (Tabela 1) é possível observar que o número de ingressantes aumentou, assim como todos os índices de evasão.

Diante do cenário observado, fixou-se como meta de índice de evasão (atividade 2.3) aceitável para o próximo período (2018) os montantes de $50 \%$ para a \%Evasãoingressantes e $10 \%$ para a \%Evasãodemais estudantes. Inicialmente, decidiu-se por metas não tão rigorosas, visto que se tratava da primeira aplicação do ciclo, além do foco nos ingressantes que apresentavam o maior índice de desistência.

\section{Aplicação da etapa C - Combater}

Para realização da atividade 3.1 (planejamento das ações de combate) foi criado o plano de ação 5W1H (Quadro 5). Quando tal atividade foi desenvolvida, o Colegiado já possuía algumas ações que poderiam ser classificadas como diminutivas de evasão. Estas, entretanto, não eram realizadas com esse foco (oferta de bolsas de estudos e cursos preparatórios; realização de evento de acolhida aos ingressantes, monitorias em disciplinas, visitas técnicas, etc.).

Quadro 5 - Plano de ação 5W1H de combate a evasão

\begin{tabular}{|c|c|c|c|c|c|}
\hline O QUE? & POR QUÊ? & QUEM? & ONDE? & QUANDO? & COMO? \\
\hline $\begin{array}{l}\text { Divulgar o curso } \\
\text { em redes sociais }\end{array}$ & $\begin{array}{c}\text { O Curso não tem um canal de } \\
\text { comunicação que informe a } \\
\text { respeito de seus objetivos e } \\
\text { ações gerais }\end{array}$ & $\begin{array}{l}\text { Professor do } \\
\text { Colegiado e } \\
\text { equipe de } \\
\text { alunos } \\
\end{array}$ & $\begin{array}{l}\text { Departamento } \\
\text { de Engenharia } \\
\text { de Produção }\end{array}$ & $\begin{array}{c}\text { Durante o } \\
\text { período letivo }\end{array}$ & $\begin{array}{c}\text { Publicar informes e ações } \\
\text { gerais do curso em redes } \\
\text { sociais }\end{array}$ \\
\hline $\begin{array}{l}\text { Ofertar a } \\
\text { Semana da } \\
\text { Revisão } \\
\text { Bimestral }\end{array}$ & $\begin{array}{l}\text { Em meio a tantas informações } \\
\text { e disciplinas, os alunos } \\
\text { cometem erros básicos nas } \\
\text { resoluções das provas, } \\
\text { repercutindo em notas baixas } \\
\end{array}$ & $\begin{array}{c}\text { Professor da } \\
\text { disciplina }\end{array}$ & Salas de aula & $\begin{array}{c}\text { Na semana } \\
\text { que antecede a } \\
\text { avaliação } \\
\text { bimestral }\end{array}$ & $\begin{array}{c}\text { Revisar todo o conteúdo } \\
\text { do bimestre }\end{array}$ \\
\hline $\begin{array}{l}\text { Ofertar a } \\
\text { Semana da } \\
\text { Revisão Geral }\end{array}$ & $\begin{array}{l}\text { Em meio a tantas informações } \\
\text { e disciplinas, os alunos } \\
\text { cometem erros básicos nas } \\
\text { resoluções das provas, } \\
\text { repercutindo em notas baixas }\end{array}$ & $\begin{array}{c}\text { Professor da } \\
\text { disciplina }\end{array}$ & Salas de aula & $\begin{array}{l}\text { Na semana } \\
\text { que antecede a } \\
\text { aplicação do } \\
\text { Exame anual }\end{array}$ & $\begin{array}{l}\text { Revisar todo o conteúdo } \\
\text { anual }\end{array}$ \\
\hline $\begin{array}{l}\text { Aplicar testes de } \\
\text { interesses para } \\
\text { alunos do Ensino } \\
\text { Médio (público } \\
\text { alvo) } \\
\end{array}$ & $\begin{array}{l}\text { Os alunos não conhecem suas } \\
\text { habilidades em relação à sua } \\
\text { vocação profissional, profissão } \\
\text { do engenheiro de produção e } \\
\text { particularidades do Curso } \\
\end{array}$ & $\begin{array}{l}\text { Professor do } \\
\text { colegiado e } \\
\text { equipe de } \\
\text { alunos }\end{array}$ & $\begin{array}{l}\text { Escolas do } \\
\text { público alvo }\end{array}$ & $\begin{array}{l}\text { Nos meses } \\
\text { que } \\
\text { antecedem o } \\
\text { vestibular }\end{array}$ & $\begin{array}{c}\text { Aplicar testes de interesse } \\
\text { para os alunos, de forma } \\
\text { presencial }\end{array}$ \\
\hline $\begin{array}{l}\text { Envolver } \\
\text { estudantes em } \\
\text { projetos }\end{array}$ & $\begin{array}{c}\text { Os alunos precisam ser } \\
\text { estimulados e engajados em } \\
\text { ações e assuntos que envolvam } \\
\text { a engenharia de produção } \\
\end{array}$ & Professores & $\begin{array}{l}\text { Departamento } \\
\text { de Engenharia } \\
\text { de Produção }\end{array}$ & $\begin{array}{c}\text { Durante o } \\
\text { período letivo }\end{array}$ & $\begin{array}{l}\text { Inserir alunos como } \\
\text { pesquisadores em } \\
\text { projetos de ensino, } \\
\text { pesquisa e extensão }\end{array}$ \\
\hline $\begin{array}{l}\text { Fomentar } \\
\text { participativida- } \\
\text { de no evento de } \\
\text { acolhida aos } \\
\text { ingressantes }\end{array}$ & $\begin{array}{c}\text { É importante integrar o } \\
\text { ingressante formalmente } \\
\text { (integração acadêmica) e } \\
\text { informalmente (integração } \\
\text { social), por meio da vivência } \\
\text { com professores e veteranos }\end{array}$ & $\begin{array}{l}\text { Coordenação } \\
\text { do evento de } \\
\text { acolhida e } \\
\text { coordenação } \\
\text { do Colegiado }\end{array}$ & $\begin{array}{l}\text { Nos locais de } \\
\text { realização do } \\
\text { evento }\end{array}$ & $\begin{array}{l}\text { No decorrer } \\
\text { do EPA } \\
\text { Solidário }\end{array}$ & $\begin{array}{c}\text { Inserir professores e } \\
\text { alunos nas atividades do } \\
\text { evento }\end{array}$ \\
\hline $\begin{array}{l}\text { Promover } \\
\text { palestras com } \\
\text { egressos do } \\
\text { Curso de EPA }\end{array}$ & $\begin{array}{c}\text { É necessário conscientizar os } \\
\text { alunos acerca das dificuldades } \\
\text { da vida acadêmica e } \\
\text { oportunidades do mercado de } \\
\text { trabalho }\end{array}$ & $\begin{array}{l}\text { Professor do } \\
\text { colegiado e } \\
\text { equipe de } \\
\text { alunos }\end{array}$ & $\begin{array}{l}\text { Anfiteatro } \\
\text { UNESPAR }\end{array}$ & $\begin{array}{c}\text { Durante o } \\
\text { período letivo }\end{array}$ & $\begin{array}{c}\text { Organizar eventos e } \\
\text { palestras com a } \\
\text { participação de egressos }\end{array}$ \\
\hline
\end{tabular}


O Quadro 6 apresenta uma descrição de como as ações de combate foram colocadas em prática (atividade 3.2). foram utilizadas para detectar particularidades a respeito das ações desempenhadas (Quadro 7).

\section{Aplicação da etapa E - Examinar}

Na quarta e última etapa, diferentes formas de discussão com os acadêmicos (atividade 4.1)

Quadro 7 - Feedback das ações de combate à evasão realizadas durante o ano de 2017

\begin{tabular}{|c|c|c|}
\hline AÇÃO & $\begin{array}{l}\text { FORMA DE } \\
\text { CONTATO }\end{array}$ & $\begin{array}{l}\text { COMENTÁRIOS GERAIS E RELEVANTES DOS } \\
\text { PARTICIPANTES }\end{array}$ \\
\hline Divulgar o curso em redes sociais & Conversas informais & $\begin{array}{l}\text { De modo geral, a comunicação e o acesso à informação foram } \\
\text { facilitados. A sugestão foi a criação de um site para o Curso }\end{array}$ \\
\hline $\begin{array}{l}\text { Ofertar a Semana da Revisão Bimestral } \\
\text { e Ofertar a Semana da Revisão Geral }\end{array}$ & $\begin{array}{l}\text { Aplicação de } \\
\text { questionário }\end{array}$ & $\begin{array}{l}\text { 94,30\% dos entrevistados caracterizam a ação como importante } \\
\text { e } 62,90 \% \text { apontaram uma melhoria em suas médias em relação } \\
\text { ao ano anterior. Como sugestão, os participantes apontaram a } \\
\text { necessidade da adesão da ação por parte de professores que não } \\
\text { a fizeram }\end{array}$ \\
\hline $\begin{array}{l}\text { Aplicar testes de interesses para alunos } \\
\text { do Ensino Médio (público alvo) }\end{array}$ & $\begin{array}{l}\text { Apli } \\
\text { que: }\end{array}$ & $73,50 \%$ dos participantes deram feedbacks positivos \\
\hline $\begin{array}{l}\text { Envolver estudantes em projetos de } \\
\text { pesquisa e extensão }\end{array}$ & Reuniões & $\begin{array}{c}\text { Comentários positivos e sugestão de ofertar maior quantidade } \\
\text { de bolsas }\end{array}$ \\
\hline $\begin{array}{l}\text { Fomentar a participação de todos os } \\
\text { professores e alunos de todos os } \\
\text { períodos no evento de acolhida aos } \\
\text { ingressantes }\end{array}$ & Conversas informais & $\begin{array}{c}\text { Comentários positivos e sugestão de envolvimento dos } \\
\text { veteranos nas equipes competidoras }\end{array}$ \\
\hline $\begin{array}{l}\text { Promover palestras com egressos do } \\
\text { Curso de EPA }\end{array}$ & Conversas informais & $\begin{array}{c}\text { Comentários positivos e sugestão de realizar a ação mais vezes, } \\
\text { com egressos de outras áreas }\end{array}$ \\
\hline $\begin{array}{l}\text { Realizar visita técnica com os } \\
\text { ingressantes }\end{array}$ & Reuniões & $\begin{array}{l}\text { Comentários positivos e sugestão de realizar um programa de } \\
\text { visitas com destinos pré-agendados bimestralmente }\end{array}$ \\
\hline $\begin{array}{l}\text { Realizar artigos científicos com a } \\
\text { temática: evasão no ensino superior }\end{array}$ & Reuniões & $\begin{array}{l}\text { Ao ingressar no Curso, tiveram a impressão do mesmo estar em } \\
\text { decadência pelo baixo índice de ingressantes e comentários } \\
\text { relativos à evasão feitos pelos veteranos. Após as pesquisas, os } \\
\text { mesmos perceberam que essa é uma dificuldade enfrentada por } \\
\text { IES de todo país, em todos os cursos }\end{array}$ \\
\hline
\end{tabular}

Fonte: elaborado pela autora.

\section{Aplicação do Segundo Ciclo da Metodologia CACE}

As informações coletadas na aplicação do primeiro ciclo da Metodologia CACE serviram de fonte de aprimoramento para a aplicação do segundo ciclo, realizado no decorrer do ano de 2019, objetivando a coleta de dados referentes ao evadidos durante o ano de 2018.

A aplicação do primeiro ciclo foi detalhada anteriormente com o objetivo de ilustrar a utilização da Metodologia. Sendo assim, não cabe aqui o detalhamento da aplicação do segundo ciclo, mas sim a discussão de seu ponto crucial para a percepção da eficiência das ações desenvolvidas no decorrer do ano. $\mathrm{Ou}$ seja, a comparação dos índices de evasão obtidos no ciclo anterior com a meta imposta e o índice atual (Tabela 3). Por meio da comparação dos índices concluiu-se que foi possível reduzir os índices de evasão por intermédio da aplicação da Metodologia CACE. É possível observar que os índices do ano de 2018 ficaram abaixo das metas impostas, superando as expectativas. A \% Evasãoingressantes no ano de 2018 diminuiu cerca de $59,91 \%$ quando comparada ao índice do ano de 2017. Quanto a \%Evasãodemais estudantes, o índice alcançado em 2018 reduziu cerca de $57,76 \%$ quando comparada ao índice do ano de 2017. Consequentemente, a \%Evasãototal do curso também apresentou um decréscimo (cerca de 57,89\%). 
Tabela 3 - Comparação dos índices de evasão do ano de 2017 com as metas estipuladas no primeiro ciclo e com os índices de 2018

\begin{tabular}{|c|c|c|c|}
\hline VARIÁVEIS & $\begin{array}{c}\text { ÍNDICE } \\
2017\end{array}$ & $\begin{array}{l}\text { META } \\
\text { IMPOS- } \\
\text { TA }\end{array}$ & $\begin{array}{c}\text { ÍNDICE } \\
2018\end{array}$ \\
\hline $\begin{array}{l}\text { Total de } \\
\text { ingressantes }\end{array}$ & 31 & - & 29 \\
\hline $\begin{array}{l}\text { Aproveitamento } \\
\text { de vagas } \\
\text { disponibilizadas } \\
(\%)\end{array}$ & 77,50 & - & 70 \\
\hline \%Evasão ${ }_{\text {ingressantes }}$ & 77,42 & 50 & 31,03 \\
\hline $\begin{array}{l}\text { \%Evasão } \\
\text { estudantes }\end{array}$ & 13,92 & 10 & 5,88 \\
\hline $\begin{array}{l}\text { \%Evasãototal do } \\
\text { curso }\end{array}$ & 31,82 & - & 13,40 \\
\hline
\end{tabular}

Fonte: elaborada pela autora.

Esses índices servirão como base para a aplicação do próximo ciclo da Metodologia CACE, auxiliando prioritariamente na fixação da meta para o próximo período de análise, bem como para o planejamento de novas ações.

\section{CONSIDERAÇÕES FINAIS}

A evasão de alunos é um problema relevante na gestão das IES. Representa o insucesso na formação, o aumento do custo unitário por estudante, a frustração para alguns alunos e a diminuição da motivação para outros. Levando em consideração que não há uma ação global que permita quantificar, sob um mesmo critério, a evasão e suas causas, este estudo objetivou desenvolver uma metodologia de acompanhamento e de combate da evasão (Metodologia CACE) plausível de aplicação em qualquer curso de qualquer IES.

Assumindo a UNESPAR - Campus de Campo Mourão - como case da pesquisa, foram levantadas informações sobre a evasão de estudantes no curso de EPA. A partir da aplicação das quatro etapas da metodologia proposta foi possível identificar os fatores ligados à evasão, bem como definir ações e estratégias institucionais com o objetivo de combatê-la.

Cabe salientar que nenhuma das ações aqui apresentadas, isoladamente ou mesmo em conjunto, assegura a diminuição da evasão, mas todas elas constituem ações relevantes que, se bem implementadas, podem servir como auxílio para o combate do problema exposto.

Justamente por ser consequência de vários fatores, a evasão não pode ser evitada por ações pontuais. É necessário colocar o tema na pauta do planejamento pedagógico a fim de desenvolver estratégias institucionais abrangendo a discussão e acompanhamento de forma regular ao longo do ano. $\mathrm{O}$ combate à evasão deve ser encarado como um ciclo, objetivando-se a melhoria contínua. Só assim é possível identificar problemas e trabalhar as causas desse comportamento, pois o abandono dos estudos é apenas a última etapa de um processo que começa bem antes.

\section{REFERÊNCIAS}

ALVES, M. F. S.; MONTOVANI, K. L. Identificação do perfil dos acadêmicos de engenharia como uma medida de combate à evasão. Revista de Ensino de Engenharia, v. 35, n. 2, p. 26-36, 2016.

ARCE, M. E.; CRESPO, B.; MÍGUEZ-ÁLVAREZ, C. Higher Education Drop-Out in Spain Particular Case of Universities in Galicia. International Education Studies, v. 8, n. 5, 2015.

BAR-AM, R.; ARAR, O. Dropouts and Budgets: A Test of a Dropout Reduction Model among Students in Israeli Higher Education. European Journal of Educational Research. v. 6, n. 2, p.123-134, 2017.

BRASIL. Secretaria de Educação Superior e Ministério da Educação. Comissão Especial de Estudos sobre a Evasão nas Universidades Públicas Brasileiras. Brasília, $1996 . \quad$ Disponível em:.http://www.dominiopublico.gov.br/downl oad/texto/me001613.pdf. Acesso em: $21 \mathrm{dez}$. 2019.

BRASIL. Instituto Nacional de Estudos e Pesquisas Educacionais Anísio Teixeira (INEP). Censo da Educação Superior 2018: Notas estatísticas. Brasília, 2019. Disponível em: http://download.inep.gov.br/educacao_superio r/censo_superior/documentos/2019/censo_da_ 
educacao_superior_2018-

notas_estatisticas.pdf. Acesso em: 7 out. 2019.

BREIER, M. From 'financial considerations' to 'poverty': Towards a reconceptualisation of the role of finances in higher education student drop out. Higher Education, v. 60, n. 6, p. 657-670, 2010.

BUENO, J. L. O. B. A evasão de alunos. Paidéia, Ribeirão Preto, n. 5, p. 9-16, 1993.

CARVALHO, L. F.; et al. Aulas interdisciplinares como ferramenta para motivação de ingressantes em engenharia. Revista de Ensino de Engenharia, v. 37, n. 2, p. 46-51, 2018.

FECILCAM. Projeto político pedagógico do Curso de Engenharia de Produção Agroindustrial. Campo Mourão: Engenharia de Produção Agroindustrial/Fecilcam, 2010. Disponível em: http://www.fecilcam.br/index.php?option=co m_docman\&task $=$ doc_download\&gid $=2835$ \&Itemid=19. Acesso em: 29 fev. 2020.

GUIMARÃES, S. É. R.; BORUCHOVITCH, E. O estilo motivacional do professor e a motivação intrínseca dos estudantes: uma perspectiva da Teoria da Autodeterminação. Psicologia, reflexão e crítica, v. 17 , n. 2 , P. 143-150, 2004.

LOBO, M. B. de C. M. Panorama da evasão no ensino superior brasileiro: aspectos gerais das causas e soluções. In: HORTA, C. E. R. Evasão no Ensino Superior (Cadernos ABMES, 25) Brasília: Associação Brasileira de Mantenedoras de Ensino Superior, Brasília, 2012. Disponível em:.https://abmes.org.br/arquivos/publicacoes /Cadernos25.pdf>. Acesso em: 29 fev. 2020.

MARTINS, C. B. N. Evasão de alunos nos cursos de graduação em uma instituição de ensino superior. Dissertação (Mestrado em Administração) - Programa de Pós-graduação profissional em Administração, Fundação Pedro Leopoldo: Pedro Leopoldo, 2007.

MARTINS, P. G.; LAUGENI, F. Administração da Produção. 2. ed. São Paulo: Saraiva, 2005.

MORTAGY, Y.; BOGHIKIAN-WHITBY, S.; HELOU, I. An Analytical Investigation of the
Characteristics of the Dropout Students in Higher Education. Issues in Informing Science and Information Technology Education, v. 15, p. 249-278, 2018.

MIWA, S.; SHIMOSEGAWA, MINAMI. Dropout from Higher Education and Social Stratification in Japan, Annual Bulletin, Graduate School of Education, Tohoku University, v.1, p.1-18, 2015.

PEINADO, J.; GRAEML, A. R. Administração da Produção: Operações Indústrias e de Serviços. Curitiba: UniceP, 2007.

PORTO, R. C.; GONÇALVES, M. P. Motivação e envolvimento acadêmico: um estudo com estudantes universitários. Psicologia Escolar e Educacional, v. 21, n. 3, p. 515-522, 2017.

PRIM, A. L.; FÁVERO, J. D. Motivos da evasão escolar nos cursos de ensino superior de uma faculdade na cidade de Blumenau. Tecnologias para Competitividade Industrial, Florianópolis, p. 53-72, 2013.

RODRIGUES, D. G. et al. Aplicação das ferramentas da qualidade na abordagem da evasão em cursos tecnológicos. Anais... Congresso Brasileiro de Ensino em Engenharia (COBENGE), 45, 2017. Rio Grande do Norte, $2017 . \quad$ Disponível em: http://www.abenge.org.br/sis_submetidos.php ?acao $=$ abrir\&evento $=$ COBENGE $17 \&$ codigo $=$ COBENGE17_00009_00000933.pdf. Acesso em: 29 fev. 2020.

SÁNCHEZ-GELABERT, A.; ANDREU, M. A. Los estudiantes universitarios no tradicionales y el abandono de los estúdios. Estudios sobre Educación, v. 32, 2017.

SANTOS, V. M. Estilos de aprendizagem no Ensino Superior: enfrentando a evasão e a retenção. Práxis Educativa, v. 13, n. 2, p. 578595, 2018.

SANTOS JUNIOR, J. S.; REAL, G. C. M. A evasão na educação superior: o estado da arte das pesquisas no Brasil a partir de 1990. Avaliação, Campinas; Sorocaba, SP, v. 22, n. 2, p. 385-402, 2017.

UFPE. Universidade Federal de Pernambuco. Causas da evasão de alunos nos cursos de graduação presencial da UFPE. Proplan, 
Pró-reitoria de planejamento, orçamento e finanças: Recife, 2016. Disponível em: https://www.ufpe.br/documents/38954/37137 6/r_evaso_16.pdf/53642e52-41fb-4b43-b09898db6a470176. Acesso em: 18 out. 2019.
ZENORINI, R. P. C.; SANTOS, A. A. A.; MONTEIRO, R. M. Motivação para aprender: relação com o desempenho de estudantes. Paidéia, v. 21, n. 49, 157-164, 2011.

\section{DADOS BIOGRÁFICOS DOS AUTORES}

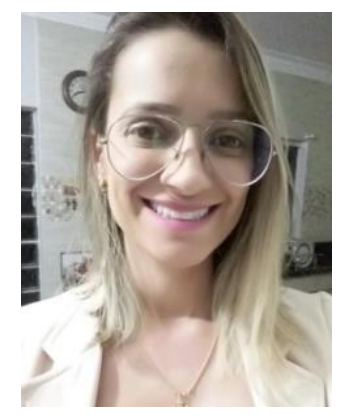

Tainara Rigotti de Castro é graduada em Engenharia de Produção Agroindustrial pela Universidade Estadual do Paraná (UNESPAR), Campus de Campo Mourão/PR (2012). Especialista em Engenharia de Segurança do Trabalho, pela Universidade Estadual de Maringá (UEM) (2014). Mestre em Engenharia Urbana pela UEM (2015), na área de concentração Planejamento e Gestão de Sistemas Urbanos. Atuou como Pesquisadora no Grupo de Pesquisa Estudos de Novos Materiais para Construção Civil, na linha de pesquisa Desenvolvimento de Novas Tecnologias em Materiais de Construção Civil. Atualmente, é professora colaboradora do Colegiado de Engenharia de Produção Agroindustrial na UNESPAR - Campus de Campo Mourão e doutoranda em Engenharia de Produção pela Universidade Tecnológica Federal do Paraná (UTFPR), Campus de Ponta Grossa. Atua em pesquisas na área de Educação em Engenharia de Produção e Desenvolvimento de Novos Produtos. 